\title{
Behavioral and Neuroanatomical Phenotypes in Mouse Models of Autism
}

\author{
Jacob Ellegood $^{1}$ • Jacqueline N. Crawley ${ }^{2}$
}

Published online: 3 June 2015

(C) The American Society for Experimental NeuroTherapeutics, Inc. 2015

\begin{abstract}
In order to understand the consequences of the mutation on behavioral and biological phenotypes relevant to autism, mutations in many of the risk genes for autism spectrum disorder have been experimentally generated in mice. Here, we summarize behavioral outcomes and neuroanatomical abnormalities, with a focus on highresolution magnetic resonance imaging of postmortem mouse brains. Results are described from multiple mouse models of autism spectrum disorder and comorbid syndromes, including the 15q11-13, 16p11.2, 22q11.2, Cntnap 2, Engrailed2, Fragile X, Integrin $\beta 3$, MET, Neurexin1a, Neuroligin3, Reelin, Rett, Shank3, Slc6a4, tuberous sclerosis, and Williams syndrome models, and inbred strains with strong autism-relevant behavioral phenotypes, including BTBR and BALB. Concomitant behavioral and neuroanatomical abnormalities can strengthen the interpretation of results from a mouse model, and may elevate the usefulness of the model system for therapeutic discovery.
\end{abstract}

Keywords Autism · Magnetic resonance imaging (MRI) · Behaviour · Neuroanatomy

Jacob Ellegood

jacob@mouseimaging.ca

Jacqueline N. Crawley

jacqueline.crawley@ucdmc.ucdavis.edu

1 Mouse Imaging Centre (MICe), Hospital for Sick Children, 25 Orde Street, Toronto, ON M5T 3H7, Canada

2 MIND Institute and Department of Psychiatry and Behavioral Sciences, University of California Davis School of Medicine, 4625 2nd Avenue, Sacramento, CA 95817, USA

\section{Introduction}

Autism is a major neurodevelopmental disorder that is diagnosed by 2 categories of behavioral abnormalities: 1) unusual reciprocal social interactions and social communication deficits; and 2) stereotyped, repetitive behaviors with restricted interests $[1,2]$. The high prevalence of autism, currently estimated at $>1 \%$ [3], underscores the need to discover the biological substrates of this unique but heterogeneous disorder, including neuroanatomical abnormalities.

Genetic, epigenetic, and environmental causes of autism are under intense investigation. Large numbers of de novo genetic mutations and copy number variants are associated with autism $[4,5]$. To understand the role of each gene and chromosomal locus in the symptoms of autism, mutations in homologous genes have been generated in many knockout (KO) and knockin (KI) mice, and several $\mathrm{KO}$ rats $[6,7]$. The initial fundamental question was how to assay autism-relevant behaviors in mice and rats. Our group (JNC) took on this challenge, beginning in 2000 , by developing a set of mouse social behavior assays relevant to social approach and appropriate reciprocal interactions, olfactory and ultrasonic vocalization analyses of potential relevance to social communication, and quantitative measures of spontaneous motor stereotypies and repetitive behaviors, along with assessments of mouse behavioral domains relevant to some of the associated symptoms of autism, including intellectual disabilities, anxiety, sensory reactivity, and hyperactivity [6, 8-14]. These behavioral tests, with high face validity to the diagnostic and associated symptoms of autism, have been widely applied by our laboratory and others to investigate a broad range of genetic mouse models of autism and related neurodevelopmental disorders, as described below and in Table 1. Simultaneously, our Mouse Imaging Centre (J.E.) began systematically evaluating structural neuroanatomy in a 
Table 1 Examples of currently published neuroanatomical assessments, using magnetic resonance imaging (MRI), and behavioral assessments in mouse models related to autism

\begin{tabular}{|c|c|c|c|c|c|}
\hline & Model & $\begin{array}{l}\text { MRI/DTI neuroanatomical } \\
\text { abnormalities*(yes/no) }\end{array}$ & Reference(s) & $\begin{array}{l}\text { Low social and/or repetitive } \\
\text { behaviors (yes/no) }\end{array}$ & Reference(s) \\
\hline \multicolumn{6}{|l|}{ Comorbid syndromes } \\
\hline $15 q 11-13$ & $15 q 11-13(\mathrm{patDp} /+)$ & Yes & [144] & Yes & [143] \\
\hline \multirow{2}{*}{$\begin{array}{l}\text { 16p11.2 deletion and } \\
\text { duplication }\end{array}$} & $16 \mathrm{p} 11.2$ deletion $(+/-)$ & Yes & [28] & No & [28] \\
\hline & $\begin{array}{l}\text { 16p11.2 (df/+), }(\mathrm{dp} /+), \\
(\mathrm{df} / \mathrm{dp})\end{array}$ & Yes & [54] & $\dagger$ & \\
\hline $22 \mathrm{q} 11.2$ & $22 \mathrm{q} 11.2(\mathrm{df} /+)$ & Yes & [159] & No & [160] \\
\hline \multirow[t]{3}{*}{ FXS } & $F m r l(-/ \mathrm{y})(\mathrm{B} 6)$ & No & [115] & Yes & [161] \\
\hline & & Yes & {$[130,162]$} & No & {$[30,69]$} \\
\hline & Fmrl (-/y) (FVB) & Yes & Submitted [163] & $\dagger$ & \\
\hline \multirow[t]{3}{*}{ Rett syndrome } & Mecp2 (-/y) - null & Yes & {$[116,120,121]$} & Yes & [164] \\
\hline & & & & No & {$[165,166]$} \\
\hline & $\operatorname{Mecp2~(-/y)-308~}$ & Yes & {$[163,167]$} & Yes & {$[168]$} \\
\hline Tuberous sclerosis & $T s c 1(+/-)$ & $\mathrm{No}^{*}$ & {$[126]$} & Yes & [19] \\
\hline Turner syndrome & $\mathrm{XO}$ & Yes & {$[163,169]$} & $\dagger$ & \\
\hline Williams syndrome & $\begin{array}{l}\text { Gtf2i (dp/dp) } \\
\text { Gtf } 2 i(+/-)\end{array}$ & Yes & {$[163]$} & $\dagger$ & \\
\hline \multicolumn{6}{|l|}{ Genetic associations } \\
\hline Androgen receptor & $\begin{array}{l}\operatorname{AndR}(12 \mathrm{Q} / \mathrm{y}) \\
\operatorname{AndR}(48 \mathrm{Q} / \mathrm{y})\end{array}$ & Yes & [163] & $\dagger$ & \\
\hline CNTNAP2 & Cntnap2 (-/-) & No & [163] & Yes & [17] \\
\hline Engrailed2 & $\operatorname{En} 2(-/-)$ & Yes & [163] & Yes & [20] \\
\hline Ephrin-A & EphrinA2(-/-)A3(-/-) & $\dagger$ & & Yes & [27] \\
\hline Integrin $\beta 3$ & $\operatorname{Itg} \beta 3(-/-)$ & Yes & {$[133,167]$} & Yes & [64] \\
\hline Gabrb3 & Gabrb3 (-/-) & $\dagger$ & & Yes & [21] \\
\hline MET & Met-fx & Yes & {$[170]$} & $\dagger$ & \\
\hline Neurexin $1 \alpha$ & $\begin{array}{l}\operatorname{Nrxn1\alpha }(+/-) \\
\operatorname{Nrxn1\alpha }(-/-)\end{array}$ & Yes & [163] & Yes & {$[171,172]$} \\
\hline Neuroligin2 & $\begin{array}{l}N l 2(+/-) \\
N l 2(-/-)\end{array}$ & $\dagger$ & & No & [26] \\
\hline \multirow[t]{2}{*}{ Neuroligin 3} & $N l 3(-/ y)$ & No & {$[125]$} & No & {$[125]$} \\
\hline & $N l 3(-/ \mathrm{y}) \mathrm{R} 451 \mathrm{C} \mathrm{KI}$ & Yes & {$[131,132,167]$} & No, Yes & [31-33] \\
\hline Oxytocin & $\begin{array}{l}\text { Oxt }(+/-) \\
\text { Oxt }(-/-)\end{array}$ & $\dagger$ & & No & [24] \\
\hline Oxytocin receptor & $\operatorname{Oxtr}(-/-)$ & $\dagger$ & & Yes & [23] \\
\hline Pten & Pten $(+/-)$ & $\dagger$ & & Yes & [18] \\
\hline Reelin & Reln & Yes & [173] & No & [173] \\
\hline Ube3a & Ube $3 a(2 \mathrm{XTg})$ & $\dagger$ & & Yes & {$[22]$} \\
\hline Shank1 & $\begin{array}{l}\text { Shankl (+/-) } \\
\text { Shankl (-/-) }\end{array}$ & $\dagger$ & & No & [25] \\
\hline Shank3 Exon 4-9 & $\begin{array}{l}\text { Shank3 }(+/-) \\
\text { Shank3 }(-/-)\end{array}$ & Yes & [163] & Yes & {$[15,16,47,174,175]$} \\
\hline \multirow[t]{2}{*}{ Slc6a4 (SERT) } & $\begin{array}{l}\text { Slc6a4 (-/-) } \\
\text { Slc6a4 (Ala56/Ala56) }\end{array}$ & No & [163] & Yes & [29] \\
\hline & (B6), (129) & & & & \\
\hline \multicolumn{6}{|l|}{ Inbred strains } \\
\hline $\mathrm{BALB} / \mathrm{cJ}$ & $\mathrm{BALBC} / \mathrm{J}$ & Yes & [154] & Yes & {$[45,46]$} \\
\hline BTBR & BTBR & Yes & {$[149,151,152]$} & Yes & {$[10,12,37-40,42-44,52]$} \\
\hline $\mathrm{C} 58 / \mathrm{J}$ & C58 & $\dagger$ & & Yes & {$[58]$} \\
\hline Deer mice & Deer Mice & $\dagger$ & & Yes & [59] \\
\hline
\end{tabular}

FXS fragile X syndrome; SERT Serotonin Transporter

*Neuroanatomical abnormalities mentioned here are defined by volumetric differences as measured by MRI and/or fractional anisotropy/mean diffusivity differences as measured with diffusion tensor imaging (DTI)

${ }^{\dagger}$ Experiments not done or not published

${ }^{\ddagger}$ It should be noted that while the paper on tuberous sclerosis reported no measures in volume and/or the DTI metrics of interest there were other neurological findings 
broad range of genetic mouse models of autism and related neurodevelopmental disorders, as described below and in Table 1.

This article will review results to date, and discuss the advantages of a combined behavioral and neuroanatomical approach to understanding the consequences of a genetic mutation found in people with autism. For the purposes of this review we will examine a large number of mouse models of autism spectrum disorder (ASD). These include: 1) models that are genetically associated with autism or related to human genes associated with autism, such as the SHANK3 mutation, which appears in a relatively large number of cases of autism and is central to Phelan-McDermid syndrome; 2) models that represent comorbid syndromes, such as fragile X (FXS) and Rett, in which a small percentage of patients meet the diagnostic criteria for ASD; and 3) models that display strong behavioral face validity to ASD symptoms but have no known genetic mutations associated with ASD, analogous to idiopathic cases of autism in which no genetic mutations have been identified, such as the BTBR T+ Itpr3tf/J (BTBR) inbred strain of mice.

\section{Discoveries of Autism-relevant Behaviors in Mouse Models}

Social abnormalities are the primary diagnostic symptom and represent the most specific, consistent feature of autism. Social behavior assays have been conducted with many of the mouse models in which imaging studies were conducted. Employing our 3-chambered social approach task, a simple yes-or-no assay for sociability [13], absence of sociability was reported in mice with mutations in genes including Shank3 [15, 16], Cntnap2 [17], Pten [18], Tsc1 [19], En2 [20], Gabrb3 [21], Ube3a triplication [22], and oxytocin receptor knockouts [23]. Normal 3-chambered social approach appeared in mice with mutations in genes including oxytocin [24], Shank1 [25], Nlgn2 [26], Ephrin-A [27] and 16p11.2 deletion [28] Variable findings on social approach across laboratories and in mouse lines generated on different genetic backgrounds have been reported for mutations including Fmr1 [29, 30], Nlgn3 [31-34], and Nlgn4 [35, 36]. Social deficits on the 3-chambered sociability have been wellreplicated in 2 inbred strains of mice, BTBR [10, 12, 37-44] and Balb/cJ [45, 46].

Fine-grained, quantitative assays of reciprocal social interactions have been conducted in experimentally defined social situations for some of these mutant mouse lines. Abnormal reciprocal interactions in various social pairings were reported in several mutant lines, including Shank3 [16, 47, 48], En2 [20, 49], Gabrb3 [50], Pten [51], Tsc1 [19], and BTBR [10, $52,53]$
Stereotyped repetitive behaviors with restricted interests comprise the second diagnostic category. Spontaneous motor stereotypies in mice include high levels of circling, backflipping, vertical jumping, and sniffing one location. Repetitive behaviors in mice include unusually long bouts of self-grooming, digging, and burying foreign objects such as marbles. High levels of stereotyped or repetitive behaviors have been reported in mice with mutations in genes including Shank3 [15], 16p11.2 deletion [28, 54], Cntnap2 [17], and Ephrin-A [27] in the inbred strains of BTBR [6, 55-57], $\mathrm{C} 58 / \mathrm{J}$ [58], and in deer mice [59].

Nondiagnostic symptoms associated with autism, that is, identified in a subset of cases, include seizures, anxiety, attention deficit hyperactivity disorder, intellectual impairment, depression at older ages, unusual responses to sensory stimuli, and gastrointestinal distress. Seizures have been reported in lines of mice with mutations in Tsc1, Gbrb3, Cntnap2, Fmr1, integrin $\beta 3$ (Itg $\beta 3$ ), and others [17, 60-64]. Anxiety-related behaviors on the elevated-plus maze and other conflict tasks were seen in mice with mutations in several genes, including Nlgn2, Tsc2, Mecp2, and $\alpha$-neurexin II (Nrxn2a) [65-68]. Although anxiety is a common feature of FXS, Fmrl KO mice display low anxiety-like behaviors [69]. Low scores on learning and memory tasks such as water maze spatial navigation, fear-conditioned freezing, novel object recognition, and touchscreen visual discrimination were seen in mice with mutations in genes including Nf1, En2, 16p11.2 deletion, and Plaur with decreased gamma-aminobutryic acid-ergic cortical interneurons [20, 28, 70-72]. Further investigations of phenotypes in mice that have face validity and neuroanatomical construct validity to both diagnostic and associated symptoms of autism may prove particularly revealing.

\section{Discoveries of Neuroanatomical Abnormalities in Mouse Models of Autism}

In the human autism literature, meta-analyses examining neuroanatomical phenotypes have revealed some overlap across studies [73-76]. However, definitive interpretations remain in progress, as individual findings in vivo investigations of brains of people with autism have been replicated in some publications, but display considerable inconsistencies in many aspects. The authors of these analyses highlight several possible explanations for inconsistencies across studies, such as age and IQ, which are certainly factors; however, genetic, environmental, and behavioral heterogeneity are equally important elements. A major advantage of a model system, such as the mouse, lies in the ability to control experimentally almost all factors with tightly controlled genetics, similar environments, and standardized experimental designs.

Initial examinations of the neuroanatomy in mouse models of autism focused on comorbid syndromes related to a specific 
gene. Table 1 summarizes the neuroanatomical phenotyping that has been performed to date in mouse models related to autism. Several of those papers will be discussed in the following paragraphs.

FXS is caused by a trinucleotide repeat expansion in Xlinked FMR1. Methylation of this promoter causes a silencing of the gene and thus the loss of fragile $\mathrm{X}$ mental retardation protein expression. Similarly, the mouse model simulates this effect by knocking out Fmrl, thereby silencing the fragile X mental retardation protein protein. In FXS, $25-67 \%$ of males and $6-23 \%$ of females are also classified as having an ASD [77-79]. The Fmrl KO mouse, originally generated by the Dutch-Belgium Fragile X Consortium [80], has been widely used to conduct mechanistic studies to understand the disorder. The original 1994 study included neurological examinations that measured brain weight, with no significant differences detected. Light microscopy was employed to examine qualitative differences in several different structures, including, but not limited to, the frontal, temporal, and occipital cortices, the striatum, hypothalamus, brain stem, and cerebellum. For example, pyramidal and other neurons in the hippocampus and Purkinje cells in the cerebellum did not differ between Fmrl KO mice and their wild-type (WT) controls. The first abnormal neuroanatomical finding in the Fmrl mice was abnormal dendritic spines in the visual cortex. Using a Golgi stain, Comery et al. [81] and Irwin et al. [82] determined that the dendritic spines were longer compared with the WT, and often thin and tortuous. Similar dendritic spine shape abnormalities were reported in human patients with FXS [83].

Rett syndrome, which, like FXS, has a small percentage of patients that meet the diagnostic criteria for autism, is also related to a single genetic mutation involving $M E C P 2$. Initial neuroanatomical assessments by Guy et al. [84] determined neurological phenotypes in Rett mice. Further studies showed that the Mecp2-null mouse brains were decreased in both size and weight. Cell bodies within the hippocampus, cortex, and cerebellum were decreased in size and more densely packed. Neurons in CA2 of the hippocampus were 15-25\% smaller in the Rett mouse than WT control [85]. Further immunohistological assessments were performed by Shahbazian et al. [86], in which temporal changes of the Mecp2-null were reported in different embryonic stages.

Immunohistological investigations were performed in the late 1990s and early 2000s on several mouse models of syndromes comorbid with autism. A mouse model related to Smith-Lemli-Optiz syndrome, with a mutation in DHCR7, which encodes the terminal enzyme required for cholesterol biosynthesis, showed alterations in development of the serotonergic system [87], which relate to the common findings of hyperserotonemia in autism [88-90]. Oxytocin receptors were found to differ in several brain regions, including specific areas of the piriform, neo, and retrospenial cotices, as well as the hippocampus, in the Reeler mouse [91]. A study in the Mecp2-null mouse found delayed maturation of the neuronal architecture in the cortex [92]. While there are several benefits to using immunohistochemistry, such as the ability to examine cellular mechanisms and specific neuronal and glial differences, one of the main drawbacks is the lack of whole brain coverage and assessment. A priori knowledge is often necessary for histological assessment and even then, owing to time/cost constraints, it may only be possible to examine a limited number of regions.

When the neuroanatomical phenotype is unknown, 3dimensional (3D) imaging techniques at the mesoscopic scale (between microscopic and macroscopic) can detect very subtle differences, which can highlight an area or region of interest for further examination at the microscopic scale [93]. There are several different 3D imaging techniques that can be used to examine the mouse brain at the mesoscopic scale. Computed tomography is one example, which is often used to examine high-density structures like bone or vascular trees (filled with X-ray opaque contrast agents) [94-96], and, more recently, examine mouse embryos, which relies on the use of an iodine contrast agent to enhance the soft tissue contrast [97-99]. Ultrasound biomicroscopy, commonly used for cardiac imaging in the mouse [100-102], is also useful for studying embryonic development [103]. Positron emission tomography or single photon emission computed tomography require the use of exogenous contrast agents that can be tagged to any molecule, nanoparticle, or cell. However, positron emission tomography and single photon emission computed tomography are difficult to scale down to the mouse [104]. Optical projection tomography, basically fluorescence computed tomography, has also been used to examine fixed samples of the mouse brain and embryo [105, 106]. Lastly, magnetic resonance imaging (MRI) has been used extensively in humans, rats, and mice [107]. Examining neuroanatomical differences, using MRI, in the brains in multiple mouse models will be the focus of this neuroanatomical phenotyping review.

Arguably, MRI has the best soft tissue contrast of all the 3D techniques mentioned above. This contrast comes about because the water in different regions of the brain interacts differently with the surrounding environment. With MRI, these differences can be harnessed and the MRI sequences can be manipulated to produce several different tissue contrasts providing a wealth of information about the shape of the brain and the underlying tissue microstructure. Owing to decreased signal, as less water is present within the comparable voxel (human voxel dimensions $=1 \mathrm{~mm}$ isotropic, mouse voxel dimensions in vivo $=0.125 \mathrm{~mm}$ isotropic, ex vivo $=0.056 \mathrm{~mm}$ isotropic) required for the mouse scale, MRI is not easily scaled down from the human to the mouse. Imaging in the mouse requires significant hardware and sequence upgrades compared with standard human clinical scanners. However, despite the technical hurdles involved in mouse imaging, 
several mouse imaging centers have had success in imaging mouse brains with high neuroanatomical resolution [108-113], including ours at the Mouse Imaging Centre at the Hospital for Sick Children in Toronto [93, 94, 114].

\section{Initial Investigations with MRI (1994-2010)}

Similar to the initial histological examinations, examining the neuroanatomical phenotype started with single gene comorbid syndromes related to autism. Shortly, after the generation of the Fmrl KO mouse in 1994 [80], the first MRI neuroanatomical assessment of the Fmrl was performed [115]. Kooy et al. [115] looked at the brains of 22 anesthetized mice in vivo (11 Fmrl KO and 11 WT). Images were acquired with high spatial resolution along the long axis of the mouse brain to assess the surface area of several different structures, including the total brain, cerebellum (anterior and posterior), fourth ventricle, subcortical gray matter, and hippocampus. Additionally, 3D assessments of the entire brain, fourth ventricle, and cerebellum were calculated. No differences were found between the Fmrl KO mice and their corresponding WT. Despite this, the authors here presented a highly reproducible technique that could be used in future neuroanatomical assessments and were the first high-resolution MRI examinations of a transgenic mouse model. In 2006, Saywell et al. [116] examined the hemizygous male Mecp $2 \mathrm{KO}$ mouse. The authors calculated the volume of many different structures including the cerebellum, caudate, putamen, hippocampus, thalamus, olfactory bulbs, and lateral ventricles. In addition to these volumes, the authors also assessed the thickness of both the corpus callsoum and motor cortex. Differences throughout the brain included a smaller overall brain size and a thinner motor cortex and corpus callosum. Brain metabolism was examined with magnetic resonance spectroscopy, detecting several metabolic differences in the Mecp $2 \mathrm{KO}$ mice. This overall reduction in brain size is a common finding in the human Rett syndrome phenotype; similarly, the decreased thickness of the corpus callosum and motor cortex are also commonly found in human Rett [117-119]. However, the authors do note that the neuroanatomy of the Mecp2 KO mouse does have some differences compared with human patients. For example, the caudate nucleus and thalamus were not decreased in size in the mouse, which is a common finding in the human population. In 2008, Ward et al. [120] performed a longitudinal study on the brains of the Mecp2 KO mouse from 21 to 42 days of age. MRI was employed to calculate 4 different neuroanatomical measures: total brain volume, cerebellar volume, ventricular volume, and motor cortex thickness. Similar to the study by Saywell et al. [116], smaller total brain volumes were found in the Mecp $2 \mathrm{KO}$ mice at all time points. The cerebellar volume was also decreased initially, but was normalized at 42 days of age. Surprisingly, the motor cortex thinning that was found in the study by Saywell et al. [116] was not replicated in the study by Ward et al. [120] at any time point. The same group later assessed the response to environmental enrichment on these same regions [121]. In that study it was shown that environmental enrichment not only improved the performance of the Meсp2 $\mathrm{KO}$ mouse on several behavioral tasks, but it also showed that the ventricular volume negatively correlated with improved locomotor activity, which was the first indication of a relationship between the neuroanatomical and behavioral phenotype in a mouse model of a neurodevelopmental disorder.

The first de novo mutations found to be specifically associated with autism were in the Shank and Neuroligin families of genes [122-124]. In 2009, Radyushkin et al. [125] examined the neuroanatomy of the neuroligin $3 \mathrm{KO}$ mouse. Despite the careful measurements of the lateral and third ventricles, brainstem, olfactory bulbs, and cerebellum, the only neuroanatomical finding reported was a decrease in the total brain volume, excluding olfactory bulbs, cerebellum, and brainstem, in the Nl3 knockouts compared with WT controls.

These initial neuroanatomical studies highlighted the necessity of further investigations. All of the above studies were performed in vivo. Scan times were short and therefore the imaging resolution suffered. Accurate quantification was possible in only a small number of regions that were easily delineated. One particular study, in the tuberous sclerosis 1 heterozygous $T s c 1$ (+/-) mouse, examined ex vivo brain samples at quite high resolution [126]. However, the goal of that study was to look for cerebral lesions consistent with those found in human patients with tuberous sclerosis complex patients, and therefore no volume measurements were made.

Outside of the autism field, substantial improvements were being made in mouse imaging technology. To obtain comparable image quality in the mouse consistent with the current state of human imaging, sequences had to be optimized. That optimization and the smaller voxels needed for the mouse brain required 12-24 $\mathrm{h}$ scan times, which raised the practical need to image multiple mice in the same scan [107, 127]. Furthermore, improved image analysis techniques [94, 108, $111,128]$ and mouse atlases [129] were created to aid in the neuroanatomical analysis of the mouse. All of these improvements allowed dramatic advances in the neuroanatomical assessments in mouse model of human disease.

\section{Recent Investigations (2010-14)}

Building on these initial examinations and using the new analysis and high-throughput methods, several of the models listed above were re-examined at higher resolution in ex vivo samples. This method allowed a greater specificity in order to determine subtle changes that may or may not have been seen in the previous in vivo examinations. In 2010, the Fmrl KO mouse was revisited on a C57BL/6 J background using highresolution MRI [130], which reported volumes for 62 different 
brains regions [129], encompassing the whole brain, as well as voxel-wise differences that highlight local differences found within those regions [128]. Similar to the initial Fmrl examination by Kooy et al. [115], no differences were found in total brain volume. However, in 3 specific regions of interest, trends were seen for a larger parietotemporal lobe and a smaller striatum, and a significantly smaller arbor vita (white matter and deep cerebellar nuclei) of the cerebellum was detected. Further investigation into the differences in the cerebellum were localized in the fastigial nucleus and nucleus interpositus. These changes were also examined using histology to determine the cause of the volume differences in these regions. Loss of neurons and a subsequent increase in astrocytes due to reactive gliosis was determined to be responsible for the differences. This work demonstrates that neuroanatomical imaging using MRI is not the end of the investigation. Rather, MRI results highlight possible areas of interest within the brain that can be investigated further. This work also showed the ability of high-resolution ex vivo MRI to detect subtle phenotypes in mouse models related to autism.

The Neuroligin 3 mutation, was also re-examined, with the Neuroligin3 R415C KI (Nl3 KI) mouse model [131], which is related to a specific human mutation found in a Swedish family [122]. Similar to the original study done in 2009, a reduced total brain volume was found. Moreover, of the 62 regions examined, 20 were found to be significantly different. The most significant regional differences were a smaller hippocampus, striatum, and thalamus. Several white matter regions were smaller, including the corpus callosum, fimbria, fornix, and internal capsule, all of which contributed significantly to the overall white matter deficit of $8 \%$. These findings were recently replicated in 2014 by Kumar et al. [132], using a larger sample with 3 different ages.

In 2012, Ellegood et al. [133] also examined the $\operatorname{Itg} \beta 3 \mathrm{KO}$ mouse model. Similar to the $N l 3 \mathrm{KI}$ model, the $\operatorname{Ig} \beta 3$ model had a smaller total brain volume and a considerable white matter deficit, with 16 of the 23 white matter structures in the atlas found to be significantly smaller. Further, the corpus callosum differences found in the $\operatorname{Itg} \beta 3$ mouse model were remarkably similar to those changes found in the Nl3 KI model. White matter differences have become a common finding in human autism, leading to speculation that children experience a period of abnormal white matter development [134]. Also, connectivity deficits are commonly reported in the autistic population where connectivity is measured either functionally [with functional MRI (fMRI)] or anatomically [with diffusion tensor imaging (DTI) metrics]. This abnormal connectivity has been reported to be both decreased and underdeveloped [135-137], or overconnected in human autism [138]. Findings in both the $N l 3 \mathrm{KI}$ and $\operatorname{Itg} \beta 3$ models were consistent with a decreased anatomical connectivity in these mice.

Copy number variations are quite common in the human population, and several specific copy number variants have been associated with autism. Mouse models of 15q11-13, 16p11.2, and 22q11.2 have all been linked to autism and neuroanatomically examined using MRI. Horev et al. [54] generated 3 different syntenic mouse models, a 16p11.2 deletion $(\mathrm{df} /+)$, a duplication $(\mathrm{dp} /+)$, and a deletion/duplication $(\mathrm{df} / \mathrm{dp})$. Significant relative volume differences were found only in the $16 \mathrm{p} 11.2(\mathrm{df} /+)$ model in 8 different regions. These regions were localized to subcortical midline structures including the basal forebrain, medial septum, midbrain, and hypothalamus, all of which were found to be larger than their corresponding WT. There was also an apparent dosage affect, where the $16 \mathrm{p} 11.2(\mathrm{df} /+)$ was larger than the WT that was larger than the $16 \mathrm{p} 11.2(\mathrm{dp} /+)$. The $16 \mathrm{p} 11.2$ deletion was recently re-examined on a different background that was independently generated [28]. Portmann et al. [28] examined the 16p11.2 deletion $(+/-)$ model at a different age (postnatal day 7) than Horev et al. [54]; however, similar to the study by Horev et al. [54], several relative volume increases were seen in midline structures throughout the brain [28]. Comparisons between the voxel-wise maps between both $16 \mathrm{p} 11.2$ deletion studies showed remarkable overlap considering the different generation of the mice, as well as different backgrounds, ages, and sex.

The 22q11.2 deletion $(\mathrm{df} /+)$, which is related to both schizophrenia and autism, and the 15q11-13 duplication models have also been recently examined. The 22q11.2 deletion mouse model displayed several differences that mirrored what has been found in human 22q11.2 deletion syndrome [139-141]. Specifically, the larger striatum, smaller cerebellum, and smaller amygdala in the mouse model are all consistently found in human patients. Conversely, the 15q11-13 duplication mouse model, which was examined with both a maternal and paternal duplication, did not necessarily replicate what is seen in the human population, as the majority of human patients with 15q11-13 duplication have maternally inherited duplications [142]. The differences found in the mice, both behaviorally and neuroanatomically [143, 144], were found only in the paternally inherited duplication. Interestingly, there has been increasing evidence for paternally inherited 15q11-13 duplications in patients with autism [145, 146]. These studies highlight the importance of both construct and face validity in examining mouse models related to human disease.

In addition to the genetically associated mouse models related to autism, several inbred strains of mice display autismrelevant behavioral phenotypes, including unusually low social and unusually high repetitive scores. The most well described and examined is the BTBR T+ Itpr3tf/J (BTBR) inbred strain, in which deficits in a variety of social tasks, along with high repetitive self-grooming, marble burying, and digging, have been replicated by many laboratories $[10,37,38$, 40]. In addition, the BALB/cJ (BALB) inbred strain displays 
strong social deficits at juvenile ages [45, 147, 148], and the $\mathrm{C} 58 / \mathrm{J}$ inbred strain displays repetitive jumping [52]. The fact that the models are inbred strains without known genetic abnormalities reflecting risk genes for autism poses an issue for the selection of the appropriate control, but normally the behavioral comparisons were made against the C57BL/6 J (B6) inbred strain, which is a commonly used background strain with normal social behaviors and low repetitive behaviors. The BTBR mouse has been examined in 3 different studies. The first compared the BTBR mouse with both C57BL/6 J and FVB/AntJ [149], investigating both volume differences and tissue microstructure differences using DTI. DTI is a technique that examines the underlying tissue microstructure based on the diffusion of water throughout the brain. The most striking difference between BTBR and both of the control strains was the almost complete lack of a corpus callosum, as previously reported [150]. Cerebral white matter as a whole was significantly reduced, specifically 10 of 14 with matter regions were smaller. Dodero et al. [151] replicated what was found in the study by Ellegood et al. [133], similarly comparing BTBR with B6, but also reported resting-state fMRI connectivity differences in the BTBR mouse, including a significant reduction in the cerebral blood volume that is indicative of a reduced basal metabolism. The same group also examined dopaminergic neurotransmission in BTBR mice using fMRI, highlighting possible dysfunctions in the dopaminergic system [152]. These findings in BTBR mice implicate abnormalities in white matter, in particular interhemispheric connections, as common phenotypes across mouse models of autism. Regions implicated in these mouse model studies have also been reported in human autism studies and support the validity of mouse phenotyping strategies.

Two studies that examined the BALB mouse evaluated neuroanatomy with DTI $[153,154]$. Kim et al. [153] measured the fractional anisotropy (FA; a measure of order in the tissue) and mean diffusivity (MD; a measure of the average diffusivity of water) in the BALB mouse. In several white and gray matter regions, FA and MD correlated with the social scores [153]. The second study, by Kumar et al. [154], examined FA and MD differences between BALB and B6 mice in 8 different gray and white matter structures at several different time points. Differences were found in the corpus callosum, external capsule, cortex, hippocampus, and amygdala. The authors highlighted several findings that were consistent with human autism.

\section{Large-scale Discovery (2014)}

In 2014, a collaboration between 16 different centers and 34 different researchers examined 26 different mouse models related to ASD. This study hypothesized that by clustering autism based solely on the neuroanatomy, and identifying strong connections based on those models, similarities would be discovered that could provide neuroanatomical biomarkers for predicting treatment response. Choices derived from all 3 categories mentioned above: comorbid syndromes, genetic associations, and inbred strains with autism-relevant behavioral phenotypes. The 26 models were clustered into 3 different groups based on their neuroanatomical phenotype. Group 1 [consisting of En2 and Fmrl (on both the FVB and B6 backgrounds), Nrxn1 $\alpha$, and Shank3] had increases in large white matter structures, including the corpus callosum, fimbria, and fornix, as well as increases in the frontal and parietotemporal lobe and decreases in the cerebellar cortex. Conversely, group 2 [consisting of $A n d R$, BTBR, Gtf2i (dp/dp), Itg $33,15 \mathrm{q} 11-13$, Slc6A4 KI (129 background), and Nl3 KI] had decreases in white matter structures such as the cerebral peduncle, corpus callosum, and internal capsule, as well as the globus pallidus, hippocampus, and striatum. Group 3 [consisting of $16 \mathrm{p} 11$, BALB/c, Cntnap2 (-l-), Gtf2i (+/-), Mecp2, Slc6A4 KI (B6 background), Slc $6 A 4 \mathrm{KO}$, and XO] had a mixture of increases and decreases, where the frontal and parietotemporal lobes were decreased in size and the cerebellum was increased. An overarching outcome of this large-scale project was the recognition that the neuroanatomical heterogeneity across cases of autism in the human population is similarly present across the multiple mouse models related to autism. Similarities and differences across the 26 models highlighted the parietotemporal lobe, frontal lobe, cerebellum, hypothalamus, and striatum as the most affected regions across models, all of which have been implicated in human autism. Furthermore, the models were stratified into subgroups with similar neuroanatomical abnormalities, which suggested previously unrecognized similarities between genetic models, for example Neurexin $1 \alpha$, Fmr1, and Engrailed2.

There are several benefits in determining the neuroanatomical phenotype of a mouse model of human disease. The first major benefit is whole brain coverage, which allows examination of a mouse model without any prior knowledge. Further, several different techniques are available for the assessment of the brain using MRI. Aside from the volume differences, the underlying tissue microstructure can be assessed with DTI [131, 149, 151], functional information can be assessed using fMRI [151], and metabolic differences can be assessed with magnetic resonance spectroscopy [116].

The largest benefit of neuroanatomical imaging with MRI is the reproducibility of the findings. This can be seen with the similarities between 2 independent studies of Nl3 KI [131, 132], and the 2 independent BTBR studies [149, 151]. However, perhaps the most significant overlap is seen in the similarities between the $16 \mathrm{p} 11.2$ models [28, 54], in which the mice were created in 2 different laboratories, with 2 different techniques, and were inconsistent in age and sex, but still had strikingly similar findings. There are, however, some drawbacks to neuroanatomical phenotyping with MRI. The most significant is the lack of specificity about the cause of the 
volumetric differences. MRI neuroanatomical phenotyping is highly specific at the mesoscopic scale but the microscopic differences leading to these differences need to be investigated further with other histological methods.

When evaluating animal models of autism, an important point to note is that autism is behaviorally defined. While we can correlate anatomical findings with behavioral measures, it seems likely that recovery or improvement of symptoms will be ultimately judged based on the behavioral criteria that define autism. Behavioral deficits in the social and repetitive domain in many mouse models of autism, summarized above and in Table 1, may provide useful outcome measures for therapeutic intervention. Concomitant neuroanatomical and behavioral deficits in the same mouse models may offer 2 linked outcome measures to evaluate treatment efficacy. Several studies to examine that possibility are currently underway. While developmental treatments could have a profound effect on neuroanatomy at a young age when there is pronounced plasticity, treatment may not have the same effect on neuroanatomy at an older age. Therefore, at an older age, behavioral phenotypes may be more malleable and thus the outcome measure of choice.

As displayed in Table 1, social deficits or repetitive behaviors were detected in many of the same lines of mice in which neuroanatomical abnormalities were detected. In fact, 11 of the 17 models, or $65 \%$ of the studies in Table 1 in which both measures were assessed displayed either a consistent neuroanatomical phenotype with a behavioral phenotype, or were normal on both neuroanatomical and behavioral phenotypes. Had those studies been performed on the same animals, that is, behavioral testing of the animals with either in vivo imaging concurrently and/or ex vivo imaging after sacrifice, it is likely that there would be even more consistency. In a previous report, both behavioral and neuroanatomical phenotypic outcomes were detected in 17 of 19 different mouse models [155]. To build upon this further, it has been shown that behavioral training can directly influence the neuroanatomy. Lerch et al. [156] found that after only 5 days of training in the Morris water maze, highly significant volume differences in the mouse brain can be seen. Furthermore, in the BTBR study by Ellegood et al. [149], several neuroanatomical differences were found to correlate with behavioral measures across the 3 strains of mice examined [149]. For example, repetitive behaviors, specifically grooming time, in BTBR mice significantly correlated with striatal volume. Similarly, Kumar et al. [132] found significant correlations between anxiety in Nl3 KI mice and the internal capsule and medulla volumes [132]. All these examples display the tight relationship that can exist between the neuroanatomical and behavioral phenotypes.

\section{Conclusions}

The fundamental question for preclinical discovery of treatment targets for autism is the predictive value of phenotypes detected in the animal models. Three underlying issues need to be carefully addressed. First is the replicability of findings across cohorts of mice with a targeted mutation in the same gene, within the same laboratory, and across laboratories. High replicability of a strong phenotype is essential to evaluate therapeutic efficacy of an intervention. Second is the choice of phenotypes, analogous to the choice of outcome measures for clinical trials. Different schools of thought exist concerning this preclinical issue. Mouse behavioral assays with face validity to the human symptoms, such as social deficits and repetitive behaviors, have value in terms of their relevance to the human symptoms that will be used as outcome measures. Neuroanatomical, physiological, and biochemical markers that track behavioral abnormalities would elevate interpretations. Third is the match between phenotypes in the animal model and in the human disease. Evidence that the same neural circuitry and neuropharmacology underlies the mouse and the human behavioral domains will increase confidence that a pharmacological intervention, which reverses deficits in the animal model will similarly reverse deficits in the human condition. MRI and DTI imaging studies summarized in Table 1, along with the earlier histological approaches mentioned [81, 82, 85, 86, 91, 92], and forefront techniques such as optogenetics $[157,158]$, are yielding highquality information about circuitry-mediated social and repetitive behaviors in mice and humans. For example, repetitive self-grooming has shown to be correlated with the striatum, globus pallidus, and thalamus, and sociability with the frontal lobe, amygdala, and nucleus accumbens [149]. Furthermore, neuroanatomical differences have been linked to learning tasks, such as the Morris water maze, which highlighted differences in the hippocampus [156]. All these studies support the benefits of using multiple methods for investigating the differences and phenotypes in these mouse models of autism. Determining the behavioral, neuroanatomical, and histological phenotypes allows one to localize the difference, establish the cellular mechanism, and directly relate these differences to the behavior, all of which will be required for an accurate assessment of both the model and possible rescues by interventions.

We propose that the best animal models for autism will 1) incorporate a mutation in a risk gene frequently found in individuals with ASD; 2) display well-replicated social deficits along with stereotyped or repetitive behaviors, and possibly other associated phenotypes such as seizures or cognitive deficits; 3) display well-replicated abnormalities in brain structures and pathways that recapitulate abnormalities reported in many cases of autism, or in a well-defined subgroup of autism; 4) display well-replicated abnormalities in 
electrophysiological properties in brain structures and pathways relevant to symptoms of autism; 5) display wellreplicated abnormal scores on a biological assay that is simple and quantitative, in which abnormal scores on an analogous biological measure are reported in many cases of autism or a well-defined subgroup. Confidence in the mouse model will be strongest if all of these criteria are met. However, this is a high bar to reach. The research field has not yet achieved this level of replication, assay corroboration, or biomarker validation.

The search is ongoing for autism biomarkers that appear universally in autism, or which can be used to stratify subject groups for targeted therapeutic interventions. As multiple corroborative outcome measures are elaborated, displaying concordance in human and animal studies, neuroanatomical and other biomarkers may be discovered that track with social deficits, repetitive behaviors, and other symptoms of autism in both animal models and in people with autism. Knowledge gained from the best mouse models of autism will serve to increase confidence in the usefulness of preclinical strategies for the discovery of medical treatments for autism.

Acknowledgments This work was supported by the Canadian Institute for Health Research (CIHR MOP-106418; J.E.), the Ontario Brain Institute (J.E.), the Simons Foundation Autism Research Initiative (SFARI \#204340; J.N.C.), Autism Speaks (8703; J.N.C.), and the University of California Davis Medical Investigation of Neurodevelopmental Disorders Institute (J.N.C.). J.E. acknowledges and thanks R. Mark Henkelman and Jason P. Lerch for several helpful discussions related to this work, and for their encouragement and mentorship over the years.

Required Author Forms Disclosure forms provided by the authors are available with the online version of this article.

\section{References}

1. American Psychiatric Association. The diagnostic and statistical manual of mental disorders, fifth edition. American Psychiatric Association, Arlington, VA, 2013.

2. Huerta M, Lord C. Diagnostic evaluation of autism spectrum disorders. Pediatr Clin North Am 2012;59:103-111.

3. Kim YS, Fombonne E, Koh YJ, Kim SJ. A comparison of DSMIV pervasive developmental disorder and DSM-5 autism spectrum disorder prevalence in an epidemiologic sample. J Am Acad Child Adolesc Psychiatry 2014;53:500-508

4. Huguet G, Ey E, Bourgeron T. The genetic landscapes of autism spectrum disorders. Annu Rev Genomics Hum Genet 2013;14: 191-213.

5. Jeste SS, Geschwind DH. Disentangling the heterogeneity of autism spectrum disorder through genetic findings. Nat Rev Neurol 2014; 10:74-81

6. Silverman JL, Yang M, Lord C, Crawley JN. Behavioural phenotyping assays for mouse models of autism. Nat Rev Neurosci 2010;11:490-502.

7. Spooren W, Lindemann L, Ghosh A. Synapse dysfunction in autism: a molecular medicine approach to drug discovery in neurodevelopmental disorders. Trends Pharmacological Sci 2012;33:669-684.
8. Crawley JN. Designing mouse behavioral tasks relevant to autistic-like behaviors. Ment Retard Dev Disabil Res Rev 2005;10:248-258

9. Moy SS, Nadler JJ, Perez A, Barbaro RP. Sociability and preference for social novelty in five inbred strains: an approach to assess autistic-like behavior in mice. Genes Brain Behav 2004;3:287302.

10. McFarlane HG, Kusek GK, Yang M, Phoenix JL, Bolivar VJ, Crawley JN. Autism-like behavioral phenotypes in BTBR T $+\mathrm{tf} / \mathrm{J}$ mice. Genes Brain Behav 2008;7:152-163.

11. Scattoni ML, Ricceri L, Crawley JN. Unusual repertoire of vocalizations in adult BTBR $\mathrm{T}+\mathrm{tf} / \mathrm{J}$ mice during three types of social encounters. Genes Brain Behav 2011;10:44-56.

12. Wöhr M, Roullet FI, Crawley JN. Reduced scent marking and ultrasonic vocalizations in the BTBR T+tf/J mouse model of autism. Genes Brain Behav 2011;10:35-43.

13. Yang M, Silverman JL, Crawley JN. Automated three-chambered social approach task for mice. Curr Protoc Neurosci 2011; Chapter 8: Unit 8.26.

14. Crawley JN. Translational animal models of autism and neurodevelopmental disorders. Dialogues Clin Neurosci 2012;14:293-305.

15. Peça J, Feliciano C, Ting JT, et al. Shank3 mutant mice display autistic-like behaviours and striatal dysfunction. Nature 2011;472: 437-442.

16. Yang M, Bozdagi O, Scattoni ML, et al. Reduced excitatory neurotransmission and mild autism-relevant phenotypes in adolescent Shank3 null mutant mice. J Neurosci 2012;32: 6525-6541.

17. Peñagarikano $\mathrm{O}$, Abrahams BS, Herman EI, et al. Absence of CNTNAP2 leads to epilepsy, neuronal migration abnormalities, and core autism-related deficits. Cell 2011;147:235-246.

18. Clipperton-Allen AE, Page DT. Pten haploinsufficient mice show broad brain overgrowth but selective impairments in autismrelevant behavioral tests. Hum Mol Genet 2014;23:3490-3505.

19. Tsai PT, Hull C, Chu Y, et al. Autistic-like behaviour and cerebellar dysfunction in Purkinje cell Tsc1 mutant mice. Nature 2012;488:647-651.

20. Brielmaier J, Matteson PG, Silverman JL, et al. Autism-relevant social abnormalities and cognitive deficits in engrailed-2 knockout mice. PLoS ONE 2012;7:e40914.

21. DeLorey TM, Sahbaie P, Hashemi E, Homanics GE, Clark JD. Gabrb3 gene deficient mice exhibit impaired social and exploratory behaviors, deficits in non-selective attention and hypoplasia of cerebellar vermal lobules: a potential model of autism spectrum disorder. Behavioural Brain Research 2008;187:207-220.

22. Smith SEP, Zhou Y-D, Zhang G, Jin Z, Stoppel DC, Anderson MP. Increased gene dosage of Ube 3 a results in autism traits and decreased glutamate synaptic transmission in mice. Sci Transl Med 2011;3:103ra97.

23. Pobbe RLH, Pearson BL, Defensor EB, et al. Oxytocin receptor knockout mice display deficits in the expression of autism-related behaviors. Horm Behav 2012;61:436-444.

24. Crawley JN, Chen T, Puri A, et al. Social approach behaviors in oxytocin knockout mice: comparison of two independent lines tested in different laboratory environments. Neuropeptides 2007;41:145-163.

25. Silverman JL, Turner SM, Barkan CL, et al. Sociability and motor functions in Shank1 mutant mice. Brain Res 2011;1380:120-137.

26. Wöhr M, Silverman JL, Scattoni ML, et al. Developmental delays and reduced pup ultrasonic vocalizations but normal sociability in mice lacking the postsynaptic cell adhesion protein neuroligin2. Behav Brain Res 2013;251:50-64.

27. Wurzman R, Forcelli PA, Griffey CJ, Kromer LF. Repetitive grooming and sensorimotor abnormalities in an ephrin-A knockout model for Autism Spectrum Disorders. Behav Brain Res 2014;278C:115-128. 
28. Portmann T, Yang M, Mao R, et al. Behavioral abnormalities and circuit defects in the basal ganglia of a mouse model of 16p11.2 deletion syndrome. Cell Rep 2014;7:1077-1092.

29. Moy SS, Nadler JJ, Young NB, et al. Social approach in genetically engineered mouse lines relevant to autism. Genes Brain Behav 2009;8:129-142.

30. Spencer CM, Alekseyenko O, Hamilton SM, et al. Modifying behavioral phenotypes in Fmr1KO mice: genetic background differences reveal autistic-like responses. Autism Res 2011;4:40-56.

31. Tabuchi K, Blundell J, Etherton MR, et al. A neuroligin-3 mutation implicated in autism increases inhibitory synaptic transmission in mice. Science 2007;318:71-76.

32. Chadman KK, Gong S, Scattoni ML, et al. Minimal aberrant behavioral phenotypes of neuroligin-3 R451C knockin mice. Autism Res 2008;1:147-158.

33. Etherton M, Földy C, Sharma M, et al. Autism-linked neuroligin-3 R451C mutation differentially alters hippocampal and cortical synaptic function. Proc Natl Acad Sci USA 2011;108:1376413769.

34. Jaramillo TC, Liu S, Pettersen A, Birnbaum SG, Powell CM. Autism-related neuroligin-3 mutation alters social behavior and spatial learning. Autism Res 2014;7:264-272.

35. Ey E, Yang M, Katz AM, et al.. Absence of deficits in social behaviors and ultrasonic vocalizations in later generations of mice lacking neuroligin4. Genes Brain Behav 2012 Sep 18 [Epub ahead of print].

36. El-Kordi A, Winkler D, Hammerschmidt K, et al. Development of an autism severity score for mice using Nlgn4 null mutants as a construct-valid model of heritable monogenic autism. Behav Brain Res 2013;251:41-49.

37. Bolivar VJ, Walters SR, Phoenix JL. Assessing autism-like behavior in mice: variations in social interactions among inbred strains. Behav Brain Res 2007;176:21-26.

38. Moy SS, Nadler JJ, Young NB, et al. Mouse behavioral tasks relevant to autism: phenotypes of 10 inbred strains. Behav Brain Res 2007;176:4-20.

39. Yang M, Clarke AM, Crawley JN. Postnatal lesion evidence against a primary role for the corpus callosum in mouse sociability. Eur J Neurosci 2009;29:1663-1677.

40. Pobbe RLH, Pearson BL, Defensor EB, Bolivar VJ, Blanchard DC, Blanchard RJ. Expression of social behaviors of C57BL/6 J versus BTBR inbred mouse strains in the visible burrow system. Behav Brain Res 2010;214:443-449.

41. Silverman JL, Babineau BA, Oliver CF, Karras MN, Crawley JN. Influence of stimulant-induced hyperactivity on social approach in the BTBR mouse model of autism. Neuropharmacology 2013;68: 210-222.

42. Yang M, Abrams DN, Zhang JY, et al. Low sociability in BTBR $\mathrm{T}+\mathrm{tf} / \mathrm{J}$ mice is independent of partner strain. Physiol Behav 2012;107:649-662.

43. Burket JA, Benson AD, Tang AH, Deutsch SI. D-Cycloserine improves sociability in the BTBR T+ Itpr3tf/J mouse model of autism spectrum disorders with altered Ras/Raf/ERK1/2 signaling. Brain Res Bull 2013;96:62-70.

44. Han S, Tai C, Jones CJ, Scheuer T, Catterall WA. Enhancement of inhibitory neurotransmission by GABAA receptors having $\alpha 2,3-$ subunits ameliorates behavioral deficits in a mouse model of autism. Neuron 2014;81:1282-1289.

45. Panksepp JB, Lahvis GP. Social reward among juvenile mice. Genes Brain Behav 2007;6:661-671.

46. Fairless AH, Dow HC, Kreibich AS, et al. Sociability and brain development in BALB/cJ and C57BL/6J mice. Behav Brain Res 2012;228:299-310

47. Wang X, McCoy PA, Rodriguiz RM, et al. Synaptic dysfunction and abnormal behaviors in mice lacking major isoforms of Shank3. Hum Mol Genet 2011;20:3093-3108.
48. Bangash MA, Park JM, Melnikova T, et al. Enhanced polyubiquitination of Shank3 and NMDA receptor in a mouse model of autism. Cell 2011;145:758-772.

49. Cheh MA, Millonig JH, Roselli LM, et al. En2 knockout mice display neurobehavioral and neurochemical alterations relevant to autism spectrum disorder. Brain Res 2006;1116: 166-176.

50. Shah CR, Forsberg CG, Kang J-Q, Veenstra-VanderWeele J. Letting a typical mouse judge whether mouse social interactions are atypical. Autism Res 2013;6:212-220.

51. Kwon C-H, Luikart BW, Powell CM, et al. Pten regulates neuronal arborization and social interaction in mice. Neuron 2006;50: 377-388.

52. Silverman JL, Smith DG, Rizzo SJS, et al. Negative allosteric modulation of the mGluR5 receptor reduces repetitive behaviors and rescues social deficits in mouse models of autism. Sci Transl Med 2012;4:131ra51.

53. Burket JA, Herndon AL, Winebarger EE, Jacome LF, Deutsch SI. Complex effects of mGluR5 antagonism on sociability and stereotypic behaviors in mice: possible implications for the pharmacotherapy of autism spectrum disorders. Brain Res Bull 2011;86: 152-158.

54. Horev G, Ellegood J, Lerch JP, et al. Dosage-dependent phenotypes in models of $16 \mathrm{p} 11.2$ lesions found in autism. Proc Natl Acad Sci U S A 2011;108:17076-17081.

55. Pearson BL, Pobbe RLH, Defensor EB, et al. Motor and cognitive stereotypies in the BTBR $\mathrm{T}+\mathrm{tf} / \mathrm{J}$ mouse model of autism. Genes Brain Behav 2011;10:228-235.

56. Schwartzer JJ, Careaga M, Onore CE, Rushakoff JA, Berman RF, Ashwood P. Maternal immune activation and strain specific interactions in the development of autism-like behaviors in mice. Transl Psychiatry 2013;3:e240.

57. Amodeo DA, Yi J, Sweeney JA, Ragozzino ME. Oxotremorine treatment reduces repetitive behaviors in BTBR $\mathrm{T}+\mathrm{tf} / \mathrm{J}$ mice. Front Synaptic Neurosci 2014;6:17.

58. Ryan BC, Young NB, Crawley JN, Bodfish JW, Moy SS. Social deficits, stereotypy and early emergence of repetitive behavior in the C58/J inbred mouse strain. Behav Brain Res 2010;208:178188.

59. Lewis MH, Tanimura Y, Lee LW, Bodfish JW. Animal models of restricted repetitive behavior in autism. Behav Brain Res 2007;176:66-74

60. Meikle L, Talos DM, Onda H, et al. A mouse model of tuberous sclerosis: neuronal loss of Tsc1 causes dysplastic and ectopic neurons, reduced myelination, seizure activity, and limited survival. J Neurosci 2007;27:5546-5558.

61. Zeng L-H, Ouyang Y, Gazit V, et al. Abnormal glutamate homeostasis and impaired synaptic plasticity and learning in a mouse model of tuberous sclerosis complex. Neurobiol Dis 2007;28: 184-196.

62. Homanics GE, DeLorey TM, Firestone LL, et al. Mice devoid of gamma-aminobutyrate type A receptor beta3 subunit have epilepsy, cleft palate, and hypersensitive behavior. Proc Natl Acad Sci U S A 1997;94:4143-4148.

63. Dolen G, Osterweil E, Rao BSS, et al. Correction of fragile X syndrome in mice. Neuron 2007;56:955-962.

64. Carter MD, Shah CR, Muller CL, Crawley JN, Carneiro AMD, Veenstra-Van der Weele J. Absence of preference for social novelty and increased grooming in integrin $\beta 3$ knockout mice: initial studies and future directions. Autism Res 2011;4:57-67.

65. Blundell, J., Tabuchi, K., Bolliger, M. F., et al. Increased anxietylike behavior in mice lacking the inhibitory synapse cell adhesion molecule neuroligin 2. Genes Brain Behav 2009;8:114-126.

66. Ehninger D, Silva AJ. Increased levels of anxiety-related behaviors in a Tsc2 dominant negative transgenic mouse model of tuberous sclerosis. Behav Genet 2011;41:357-363. 
67. Samaco RC, Mandel-Brehm C, McGraw CM, Shaw CA, McGill $\mathrm{BE}, \mathrm{Zoghbi} \mathrm{HY}$. Crh and Oprm1 mediate anxiety-related behavior and social approach in a mouse model of MECP2 duplication syndrome. Nat Genet 2012;44:206-211.

68. Dachtler J, Glasper J, Cohen RN, et al. Deletion of $\alpha$-neurexin II results in autism-related behaviors in mice. Transl Psychiatry 2014; 4:e484.

69. Spencer CM, Alekseyenko O, Serysheva E, Yuva-Paylor LA, Paylor R. Altered anxiety-related and social behaviors in the Fmrl knockout mouse model of fragile $\mathrm{X}$ syndrome. Genes Brain Behav 2005;4:420-430.

70. Silva AJ, Frankland PW, Marowitz Z, et al. A mouse model for the learning and memory deficits associated with neurofibromatosis type I. Nat Genet 1997;15:281-284.

71. Brigman JL, Daut RA, Wright T, et al. GluN2B in corticostriatal circuits governs choice learning and choice shifting. Nat Neurosci 2013;16:1101-1110.

72. Bissonette GB, Schoenbaum G, Roesch MR, Powell EM. Interneurons are necessary for coordinated activity during reversal learning in orbitofrontal cortex. Biol Psychiatry 2015;77:454464.

73. Frazier TW, Hardan AY. A meta-analysis of the corpus callosum in autism. Biol Psychiatry 2009;66:935-941.

74. Via E, Radua J, Cardoner N, Happé F, Mataix-Cols D. Metaanalysis of gray matter abnormalities in autism spectrum disorder: should Asperger disorder be subsumed under a broader umbrella of autistic spectrum disorder? Arch Gen Psychiatry 2011;68:409418.

75. Radua J, Via E, Catani M, Mataix-Cols D. Voxel-based metaanalysis of regional white-matter volume differences in autism spectrum disorder versus healthy controls. Psychol Med 2010;41:1539-1550.

76. Stanfield AC, McIntosh AM, Spencer MD, Philip R, Gaur S, Lawrie SM. Towards a neuroanatomy of autism: a systematic review and meta-analysis of structural magnetic resonance imaging studies. Eur Psychiatry 2008;23:289-299.

77. Hatton DD, Sideris J, Skinner M, et al. Autistic behavior in children with fragile $\mathrm{X}$ syndrome: prevalence, stability, and the impact of FMRP. Am J Med Genet A 2006;140A:1804-1813.

78. Clifford S, Dissanayake C, Bui QM, Huggins R, Taylor AK, Loesch DZ. Autism spectrum phenotype in males and females with fragile $\mathrm{X}$ full mutation and premutation. J Autism Dev Disord 2007;37:738-747.

79. Harris SW, Hessl D, Goodlin-Jones B, et al. Autism profiles of males with fragile X syndrome. Am J Ment Retard 2008;113:427438.

80. No authors listed. Fmr1 knockout mice: a model to study fragile $\mathrm{X}$ mental retardation. The Dutch-Belgian Fragile X Consortium. Cell 1994;78:23-33.

81. Comery TA, Harris JB, Willems PJ, et al. Abnormal dendritic spines in fragile $\mathrm{X}$ knockout mice: Maturation and pruning deficits. Proc Natl Acad Sci U S A 1997;94:5401-5404.

82. Irwin SA, Galvez R, Greenough WT. Dendritic spine structural anomalies in fragile- $\mathrm{X}$ mental retardation syndrome. Cereb. Cortex 2000;10:1038-1044.

83. Irwin SA, Patel B, Idupulapati M, et al. Abnormal dendritic spine characteristics in the temporal and visual cortices of patients with fragile-X syndrome: a quantitative examination. Am J Med Genet 2001;98:161-167.

84. Guy J, Hendrich B, Holmes M, Martin JE, Bird A. A mouse Mecp2-null mutation causes neurological symptoms that mimic Rett syndrome. Nat Genet 2001;27:322-326.

85. Chen RZ, Akbarian S, Tudor M, Jaenisch R. Deficiency of methyl-CpG binding protein-2 in CNS neurons results in a Rettlike phenotype in mice. Nat Genet 2001;27:327-331.
86. Shahbazian MD, Antalffy B, Armstrong DL, Zoghbi HY. Insight into Rett syndrome: MeCP2 levels display tissue- and cell-specific differences and correlate with neuronal maturation. Hum Mol Genet 2002;11:115-124.

87. Waage-Baudet H, Lauder JM, Dehart DB. Abnormal serotonergic development in a mouse model for the Smith-Lemli-Opitz syndrome: implications for autism. Int J Dev Neurosci 2003;21:451459.

88. Young JG, Kavanagh ME, Anderson GM, Shaywitz BA, Cohen DJ. Clinical neurochemistry of autism and associated disorders. J Autism Dev Disord 1982;12:147-165.

89. Cook EH, Leventhal BL. The serotonin system in autism. Curr Opin Pediatr 1996;8:348-354.

90. Gabriele S, Sacco R, Persico AM. Blood serotonin levels in autism spectrum disorder: a systematic review and meta-analysis. Eur Neuropsychopharmacol 2014;24:919-929.

91. Liu W, Pappas GD, Carter CS. Oxytocin receptors in brain cortical regions are reduced in haploinsufficient $(+/-)$ reeler mice. Neurol Res 2005;27:339-345.

92. Fukuda T, Itoh M, Ichikawa T, Washiyama K, Goto Y-I. Delayed maturation of neuronal architecture and synaptogenesis in cerebral cortex of Mecp2-deficient mice. J Neuropathol Exp Neurol 2005;64:537-544.

93. Henkelman RM. Systems biology through mouse imaging centers: experience and new directions. Annu Rev Biomed Eng 2010;12:143-166.

94. Nieman BJ, Flenniken AM, Adamson SL, Henkelman RM, Sled JG. Anatomical phenotyping in the brain and skull of a mutant mouse by magnetic resonance imaging and computed tomography. Physiol Genomics 2006;24:154-162.

95. Kampschulte, M., Brinkmann, A., Stieger, P., et al. Quantitative $\mathrm{CT}$ imaging of the spatio-temporal distribution patterns of vasa vasorum in aortas of apoE-/-/LDL-/- double knockout mice. Atherosclerosis 2010;212:444-450.

96. Yang J, Yu LX, Rennie MY, Sled JG, Henkelman RM. Comparative structural and hemodynamic analysis of vascular trees. Am J Physiol Heart Circ Physiol 2010;298:H1249-H1259.

97. Wong MD, Dorr AE, Walls JR, Lerch JP, Henkelman RM. A novel 3D mouse embryo atlas based on micro-CT. Development 2012;139:3248-3256.

98. Metscher BD. MicroCT for developmental biology: a versatile tool for high-contrast 3D imaging at histological resolutions. Dev Dyn 2009;238:632-640.

99. Degenhardt K, Wright AC, Horng D, Padmanabhan A, Epstein JA. Rapid 3D phenotyping of cardiovascular development in mouse embryos by micro-CT with iodine staining. Circ Cardiovasc Imaging 2010;3:314-322.

100. Phoon CKL, Ji RP, Aristizábal O, et al. Embryonic heart failure in NFATc1-/- mice: novel mechanistic insights from in utero ultrasound biomicroscopy. Circ Res 2004;95:92-99.

101. Phoon CKL, Turnbull DH. Ultrasound biomicroscopy-Doppler in mouse cardiovascular development. Physiol Genomics 2003;14: $3-15$.

102. Zhou Y-Q, Foster FS, Nieman BJ, Davidson L, Chen XJ, Henkelman RM. Comprehensive transthoracic cardiac imaging in mice using ultrasound biomicroscopy with anatomical confirmation by magnetic resonance imaging. Physiol Genomics 2004;18:232-244.

103. Turnbull DH, Bloomfield TS, Baldwin HS, Foster FS, Joyner AL. Ultrasound backscatter microscope analysis of early mouse embryonic brain development. Proc Natl Acad Sci U S A 1995;92: 2239-2243.

104. Yang Y, Tai Y-C, Siegel S, et al. Optimization and performance evaluation of the microPET II scanner for in vivo small-animal imaging. Phys Med Biol 2004;49:2527-2545. 
105. Sharpe J. Optical projection tomography as a new tool for studying embryo anatomy. J Anat 2003;202:175-181.

106. Gleave,JA, Wong MD, Dazai J, et al. Neuroanatomical phenotyping of the mouse brain with three-dimensional autofluorescence imaging. Physiol Genomics 2012;44:778-785.

107. Nieman BJ, Bock NA, Bishop J, et al. Magnetic resonance imaging for detection and analysis of mouse phenotypes. NMR Biomed 2005;18:447-468.

108. Zhang J, Richards LJ, Yarowsky P, Huang H, van Zijl PCM, Mori $\mathrm{S}$. Three-dimensional anatomical characterization of the developing mouse brain by diffusion tensor microimaging. Neuroimage 2003;20:1639-1648.

109. Aggarwal M, Zhang J, Miller MI, Sidman RL, Mori S. Magnetic resonance imaging and micro-computed tomography combined atlas of developing and adult mouse brains for stereotaxic surgery. Neuroscience 2009;162:1339-1350.

110. Cyr M, Caron MG, Johnson GA, Laakso A. Magnetic resonance imaging at microscopic resolution reveals subtle morphological changes in a mouse model of dopaminergic hyperfunction. Neuroimage 2005;26:83-90

111. Johnson GA, Cofer GP, Fubara B, Gewalt SL, Hedlund LW, Maronpot RR. Magnetic resonance histology for morphologic phenotyping. J Magn Reson Imaging 2002;16:423-429.

112. Johnson GA, Ali-Sharief A, Badea A, et al. High-throughput morphologic phenotyping of the mouse brain with magnetic resonance histology. Neuroimage 2007;37:82-89.

113. Cleary JO, Wiseman FK, Norris FC, et al. Structural correlates of active-staining following magnetic resonance microscopy in the mouse brain. Neuroimage 2011;56:974-983.

114. Kovacević N, Henderson JT, Chan E, et al. A three-dimensional MRI atlas of the mouse brain with estimates of the average and variability. Cereb Cortex 2005;15:639-645.

115. Kooy RF, Reyniers E, Verhoye M, et al. Neuroanatomy of the fragile $\mathrm{X}$ knockout mouse brain studied using in vivo high resolution magnetic resonance imaging. Eur J Hum Genet 1999;7: 526-532.

116. Saywell V, Viola A, Confort-Gouny S, Le Fur Y, Villard L, Cozzone PJ. Brain magnetic resonance study of Mecp2 deletion effects on anatomy and metabolism. Biochem Biophys Res Commun 2006;340:776-783.

117. Reiss AL, Faruque F, Naidu S, et al. Neuroanatomy of Rett syndrome: a volumetric imaging study. Ann Neurol 1993;34:227234.

118. Subramaniam B, Naidu S, Reiss AL. Neuroanatomy in Rett syndrome: cerebral cortex and posterior fossa. Neurology 1997;48: 399-407.

119. Carter JC, Lanham DC, Pham D, Bibat G, Naidu S, Kaufmann WE. Selective cerebral volume reduction in Rett syndrome: a multiple-approach MR imaging study. AJNR Am J Neuroradiol 2008;29:436-441.

120. Ward BC, Agarwal S, Wang K, Berger-Sweeney J, Kolodny NH. Longitudinal brain MRI study in a mouse model of Rett Syndrome and the effects of choline. Neurobiol Dis 2008;31:110-119.

121. Nag N, Moriuchi JM, Peitzman CGK, Ward BC, Kolodny NH, Berger-Sweeney JE. Environmental enrichment alters locomotor behaviour and ventricular volume in Mecp21lox mice. Behav Brain Res 2009;196:44-48.

122. Jamain S, Quach H, Betancur C, et al. Mutations of the X-linked genes encoding neuroligins NLGN3 and NLGN4 are associated with autism. Nat Genet 2003;34:27-29.

123. Bourgeron T. A synaptic trek to autism. Curr Opin Neurobiol 2009;19:231-234.

124. Buxbaum JD. Multiple rare variants in the etiology of autism spectrum disorders. Dialogues Clin Neurosci 2009;11:35-43.
125. Radyushkin K, Hammerschmidt K, Boretius S, et al. Neuroligin3-deficient mice: model of a monogenic heritable form of autism with an olfactory deficit. Genes Brain Behav 2009;8:416-425.

126. Goorden SMI, van Woerden GM, van der Weerd L, Cheadle JP, Elgersma Y. Cognitive deficits in Tsc1+/-mice in the absence of cerebral lesions and seizures. Ann Neurol 2007;62:648-655.

127. Bock NA, Konyer NB, Henkelman RM. Multiple-mouse MRI. Magn Reson Med 2003;49:158-167.

128. Lau JC, Lerch JP, Sled JG, Henkelman RM, Evans AC, Bedell BJ Longitudinal neuroanatomical changes determined by deformation-based morphometry in a mouse model of Alzheimer's disease. Neuroimage 2008;42:19-27.

129. Dorr AE, Lerch JP, Spring S, Kabani N, Henkelman RM. High resolution three-dimensional brain atlas using an average magnetic resonance image of 40 adult $\mathrm{C} 57 \mathrm{Bl} / 6 \mathrm{~J}$ mice. Neuroimage 2008;42:60-69.

130. Ellegood J, Pacey LK, Hampson DR, Lerch JP, Henkelman RM. Anatomical phenotyping in a mouse model of fragile $\mathrm{X}$ syndrome with magnetic resonance imaging. Neuroimage 2010;53:10231029 .

131. Ellegood J, Lerch JP, Henkelman RM. Brain abnormalities in a Neuroligin3 R451C knockin mouse model associated with autism. Autism Res 2011;4:368-376.

132. Kumar M, Duda JT, Hwang W-T, et al. High resolution magnetic resonance imaging for characterization of the neuroligin-3 knockin mouse model associated with autism spectrum disorder. PLoS ONE 2014;9:e109872.

133. Ellegood J, Henkelman RM, Lerch JP. Neuroanatomical assessment of the integrin $\beta 3$ mouse model related to autism and the serotonin system using high resolution MRI. Front Psychiatry 2012;3:37.

134. Ecker C, Suckling J, Deoni SC, et al. Brain anatomy and its relationship to behavior in adults with autism spectrum disorder: a multicenter magnetic resonance imaging study. Arch Gen Psychiatry 2012;69:195-209.

135. Geschwind DH, Levitt P. Autism spectrum disorders: developmental disconnection syndromes. Curr Opin Neurobiol 2007;17: 103-111.

136. Ameis SH, Fan J, Rockel C, et al. Impaired structural connectivity of socio-emotional circuits in autism spectrum disorders: a diffusion tensor imaging study. PLoS ONE 2011;6:e28044.

137. Di Martino A, Yan C-G, Li Q, et al. The autism brain imaging data exchange: towards a large-scale evaluation of the intrinsic brain architecture in autism. Mol Psychiatry 2014;19:659-667.

138. Kana RK, Libero LE, Moore MS. Disrupted cortical connectivity theory as an explanatory model for autism spectrum disorders. Phys Life Rev 2011;8:410-437.

139. Deboer T, Wu Z, Lee A, Simon TJ. Hippocampal volume reduction in children with chromosome $22 \mathrm{q} 11.2$ deletion syndrome is associated with cognitive impairment. Behav Brain Funct 2007;3: 54.

140. Gothelf D, Michaelovsky E, Frisch A, et al. Association of the lowactivity COMT 158Met allele with ADHD and OCD in subjects with velocardiofacial syndrome. Int $\mathrm{J}$ Neuropsychopharmacol 2007;10:301-308.

141. Kates WR, Burnette CP, Bessette BA, et al. Frontal and caudate alterations in velocardiofacial syndrome (deletion at chromosome 22q11.2). J Child Neurol 2004;19:337-342.

142. Cook EH, Lindgren V, Leventhal BL, et al. Autism or atypical autism in maternally but not paternally derived proximal $15 \mathrm{q}$ duplication. Am J Hum Genet 1997;60:928-934.

143. Nakatani J, Tamada K, Hatanaka F, et al. Abnormal behavior in a chromosome-engineered mouse model for human 15q11-13 duplication seen in autism. Cell 2009;137:1235-1246.

144. Ellegood J, Nakai N, Nakatani J, Henkelman M, Takumi T, Lerch J. Neuroanatomical phenotypes are consistent with autism-like 
behavioral phenotypes in the 15q11-13 duplication mouse model. Autism Res 2015 Mar 7 [Epub ahead of print].

145. Bolton PF, Dennis NR, Browne CE, et al. The phenotypic manifestations of interstitial duplications of proximal $15 \mathrm{q}$ with special reference to the autistic spectrum disorders. Am J Med Genet 2001;105:675-685.

146. Wegiel J, Schanen NC, Cook EH, et al. Differences between the pattern of developmental abnormalities in autism associated with duplications 15q11.2-q13 and idiopathic autism. J Neuropathol Exp Neurol 2012;71:382-397.

147. Brodkin ES. BALB/c mice: low sociability and other phenotypes that may be relevant to autism. Behav Brain Res 2007;176:53-65.

148. Benson AD, Burket JA, Deutsch SI. Balb/c mice treated with Dcycloserine arouse increased social interest in conspecifics. Brain Res Bull 2013;99:95-99.

149. Ellegood J, Babineau BA, Henkelman RM, Lerch JP, Crawley JN. Neuroanatomical analysis of the BTBR mouse model of autism using magnetic resonance imaging and diffusion tensor imaging. Neuroimage 2013;70:288-300.

150. Wahlsten D, Metten P, Crabbe JC. Survey of 21 inbred mouse strains in two laboratories reveals that BTBR $\mathrm{T} /+\mathrm{tf} / \mathrm{tf}$ has severely reduced hippocampal commissure and absent corpus callosum. Brain Res 2003;971:47-54.

151. Dodero L, Damiano M, Galbusera A, et al. Neuroimaging evidence of major morpho-anatomical and functional abnormalities in the BTBR T+TF/J mouse model of autism. PLoS ONE 2013;8: e76655.

152. Squillace M, Dodero L, Federici M, et al. Dysfunctional dopaminergic neurotransmission in asocial BTBR mice. Transl Psychiatry 2014;4:e427.

153. Kim S, Pickup S, Fairless AH, et al. Association between sociability and diffusion tensor imaging in BALB/cJ mice. NMR Biomed 2012;25:104-112.

154. Kumar M, Kim S, Pickup S, et al. Longitudinal in-vivo diffusion tensor imaging for assessing brain developmental changes in $\mathrm{BALB} / \mathrm{cJ}$ mice, a model of reduced sociability relevant to autism. Brain Res 2012;1455:56-67.

155. Nieman BJ, Lerch JP, Bock NA, Chen XJ, Sled.JG, Henkelman RM. Mouse behavioral mutants have neuroimaging abnormalities. Hum Brain Mapp 2007;28:567-575.

156. Lerch, J. P., Yiu, A. P., Martinez-Canabal, A., et al. Maze training in mice induces MRI-detectable brain shape changes specific to the type of learning. Neuroimage 2011;54:2086-2095.

157. Gross M. Shining new light on the brain. Curr Biol 2011;21:R831R833.

158. Allsop SA, Vander Weele CM, Wichmann R, Tye KM. Optogenetic insights on the relationship between anxiety-related behaviors and social deficits. Front Behav Neurosci 2014;8:241.

159. Ellegood J, Markx S, Lerch JP, et al. Neuroanatomical phenotypes in a mouse model of the 22q11.2 microdeletion. Mol Psychiatry 2014;19:99-107.
160. Harper KM, Hiramoto T, Tanigaki K, et al. Alterations of social interaction through genetic and environmental manipulation of the 22q11.2 gene Sept5 in the mouse brain. Hum Mol Genet 2012;21: 3489-3499.

161. Mineur YS, Huynh LX, Crusio WE. Social behavior deficits in the Fmr1 mutant mouse. Behav Brain Res 2006;168:172-175.

162. Pacey LKK, Xuan ICY, Guan S, et al. Delayed myelination in a mouse model of fragile X syndrome. Hum Mol Genet 2013;22: 3920-3930.

163. Ellegood J, Anagnostou E, Babineau BA, et al. Clustering autism: using neuroanatomical differences in 26 mouse models to gain insight into the heterogeneity. Mol Psychiatry 2015;20:118-125.

164. Samaco RC, McGraw CM, Ward CS, Sun Y, Neul JL, Zoghbi HY. Female Mecp2(+/-) mice display robust behavioral deficits on two different genetic backgrounds providing a framework for pre-clinical studies. Hum Mol Genet 2013;22:96-109.

165. Schaevitz LR, Moriuchi JM, Nag N, Mellot TJ, Berger-Sweeney J. Cognitive and social functions and growth factors in a mouse model of Rett syndrome. Physiol Behav 2010;100:255-263.

166. Pearson BL, Defensor EB, Pobbe RLH, et al. Mecp2 truncation in male mice promotes affiliative social behavior. Behav Genet 2012;42:299-312.

167. Steadman PE, Ellegood J, Szulc KU, et al. Genetic effects on cerebellar structure across mouse models of autism using a magnetic resonance imaging atlas. Autism Res 2014;7:124-137.

168. Moretti P, Bouwknecht JA, Teague R, Paylor R, Zoghbi HY. Abnormalities of social interactions and home-cage behavior in a mouse model of Rett syndrome. Hum Mol Genet 2005;14:205220.

169. Raznahan A, Probst F, Palmert MR, Giedd JN, Lerch JP. High resolution whole brain imaging of anatomical variation in $\mathrm{XO}$, XX, and XY mice. Neuroimage 2013;83:962-968.

170. Smith JM, Xu J, Powell EM. Age dependent forebrain structural changes in mice deficient in the autism associated gene Met tyrosine kinase. Neuroimage Clin 2012;1:66-74.

171. Etherton MR, Blaiss CA, Powell CM, Südhof TC. Mouse neurexin-1alpha deletion causes correlated electrophysiological and behavioral changes consistent with cognitive impairments. Proc Natl Acad Sci U S A 2009;106:17998-18003.

172. Grayton HM, Missler M, Collier DA, Fernandes C. Altered social behaviours in neurexin $1 \alpha$ knockout mice resemble core symptoms in neurodevelopmental disorders. PLoS ONE 2013;8: e67114.

173. Michetti C, Romano E, Altabella L, et al. Mapping pathological phenotypes in reelin mutant mice. Front Pediatr 2014;2:95.

174. Roussignol G, Ango F, Romorini S, et al. Shank expression is sufficient to induce functional dendritic spine synapses in aspiny neurons. J Neurosci 2005;25:3560-3570.

175. Bozdagi O, Sakurai T, Papapetrou D, et al. Haploinsufficiency of the autism-associated Shank3 gene leads to deficits in synaptic function, social interaction, and social communication. Mol Autism 2010;1:15. 